\title{
РОЛЬ И МЕСТО НЕГОСУДАРСТВЕННЫХ СТРУКТУР БЕЗОПАСНОСТИ В СИСТЕМЕ АНТИТЕРРОРИСТИЧЕСКОЙ ЗАЩИЩЕННОСТИ СТРАНЫ
}

Аннотация. В статье анализируется место негосударственных структур безопасности и охраны в общегосударственной системе противодействия терроризму в современных условиях. Автор рассматривает противодействие терроризму в системе функций корпоративных структур безопасности.

Ключевые слова: корпоративные структуры безопасности, противодействие терроризму, система функций корпоративной безопасности.

$\mathrm{O}$ сложнение международной обстановки (вооруженные конфликты на Ближнем Востоке, активизация международного терроризма, экономическое давление в виде санкций в отношении российских предприятий за рубежом, участие российских ЧВК в Сирии) заставляет переосмыслить некоторые аспекты общегосударственной системы противодействия терроризму. В этих условиях определенные коррективы назрели в оценке роли и места негосударственных структур безопасности и частных военно-охранных организаций в общей системе антитеррористической защищенности страны. В новых условиях назрела необходимость совершенствования российского законодательства и концепций корпоративной безопасности российских компаний, прежде всего имеющих производственные единицы, представительства, логистическую структуру за рубежом.

Необходимость в совершенствовании законодательства отчасти подтверждается и потребностями практики. В 2018 г. нами проведено интервьюирование руководителей и сотрудников служб безопасности и охранных предприятий, осуществляющих корпоративную защиту некоторых лидеров российского бизнеса ${ }^{1}$. Две трети опрошенных заявили, что имеющаяся в настоящее время правовая основа не соответствует реальным возможностям подразделений безопасности и охраны по антитеррористической защите объектов, не обеспечивает должный уровень координации с правоохранительной системой страны, действующее законодательство неконкретно и декларативно.

Так, Стратегия национальной безопасности Российской Федерации до 2020 года считает, что основной угрозой является «деятельность террористических и экстремистских организаций, направленная на насильственное изменение конституционного строя Российской Федерации, дестабилизацию работы органов государственной власти, уничтожение или нарушение функционирования военных и промышленных объектов, объектов жизнеобеспечения населения, транспортной инфраструктуры, устрашение населения, в том числе путем завладения оружием массового уничтожения, радиоактивными, отравляющими, токсичными, химически и биологически опасными веществами, совершения актов ядерного терроризма, нарушения безопасности и устойчивости функционирования критической информационной инфраструктуры

1 В частности, такие опросы проводились в ходе мероприятий по повышению квалификации и учебе сотрудников ПАО «ГМК «Норильский никель», ПАО «Лукойл», ООО «Лукойл-МаринБункер», ОАО РЖД, ПАО «Аэрофлот» ПАО «Транснефть». 
Российской Федерации» ${ }^{1}$. Противодействие данным угрозам напрямую зависит от эффективности функционирования всей системы обеспечения национальной безопасности, в которую входят как государственные, так и негосударственные институты, действующие в интересах достижения необходимого уровня антитеррористической защищенности. Однако сами эти институты в Стратегии указаны лишь в самом общем виде.

Не уточняет ситуацию и Концепция противодействия терроризму в Российской Федерации, в соответствии с п. 7 которой «субъектами противодействия терроризму являются уполномоченные органы государственной власти и органы местного самоуправления, в компетенцию которых входит проведение мероприятий по противодействию терроризму, негосударственные организации и объединения, а также граждане, оказывающие содействие органам государственной власти и органам местного самоуправления в осуществлении антитеррористических мероприятий» 2 .

Как видим, указанные законы не раскрывают правового статуса, распределения ответственности и основ взаимодействия субъектов противодействия терроризму. Это приводит к пробелам и противоречиям в подзаконных нормативных актах, а нередко являются причиной правового нигилизма ${ }^{3}$.

Мы полагаем, что из всех субъектов негосударственной сферы безопасности в деятельность по противодействию терроризму в наибольшей мере вовлечены корпоративные структуры безопасности и охранные организации. В последнее время можно говорить о тенденции расширения данного перечня за счет включения в него частных военно-охранных организаций, фактически существующих, ведущих реальную работу по противодействию терроризму во многих «горячих точках», но не закрепленных в российском законодательстве 4 . Не случайно в научной литературе предлагается разработать единый закон РФ «Институты гражданского общества в системе обеспечения национальной безопасности», который систематизировал бы всю негосударственную систему обеспечения безопасности [Воронов 2017].

По нашему мнению, неконкретность законодательства отчасти объясняется недостаточной научной разработанностью проблемы.

В научной литературе различным аспектам противодействия терроризму уделяли внимание многие отечественные ученые 5 . К сожалению, явно недостаточно работ о роли негосударственной сферы безопасности при противодействии терроризму. В числе наиболее значимых теоретических трудов последнего времени, посвященных негосударственной сфере безопасности, следует отметить исследования профессора В.И. Шестакова. Основные положения данного труда, в т.ч. в части взаимодействия детективных и охранных организаций с правоохранительными органами в раскрытии преступлений, предупреждении и пресечении правонарушений, обеспечении общественной

1 Стратегия национальной безопасности Российской Федерации до 2020 года. Ст. 47.

2 Концепция противодействия терроризму в Российской Федерации от 5 октября 2009 г.

3 Например, постановлением Правительства РФ от 25.12.2013 № 1244 «Об антитеррористической защищенности объектов (территорий)» (п. 2) федеральным органам исполнительной власти предписывалось по согласованию с ФСБ и МВД России в 6-месячный срок подготовить и внести в правительство РФ проекты нормативных правовых актов, закрепляющих требования к антитеррористической защищенности объектов, правообладателями которых они являются или которые относятся к сфере их деятельности. К сожалению, не все федеральные органы исполнительной власти выполнили данное предписание в срок, а некоторые и не приступали к его согласованию.

4 Решение Комитета Государственной думы по обороне № 158/2.1 от 24 марта 2016 г. о проекте федерального закона № 1016633-6 «О частной военно-охранной деятельности».

5 Ю.И. Авдеев, А.Е. Бондаренко, А.И. Гушер, В.И. Гасумянов, Е. Давыдова, С.В. Дьяков, А. Крайнев, В.Е. Петрищев, С.В. Симаков, М. Требин, В.В. Устинов, О.М. Хлобустов, В.И. Шестаков и многие другие. 
безопасности, реализованы в ряде законопроектов ${ }^{1}$ [Шестаков 2017]. Вместе с тем следует согласиться с теми авторами, которые считают, что «несмотря на непреходящую все возрастающую значимость проблемы корпоративной безопасности в нашей стране ее научно-теоретической проработке уделяется недостаточное внимание», «пробелы в научных знаниях могут восполнить работы, посвященные ...новым подходам противодействия современному международному и внутреннему терроризму» [Гасумянов 2018: 10]. Очевидно, что деятельность корпоративных структур безопасности частных предприятий, частных детективов и охранных структур по защите от террористических угроз является наиболее значимым примером государственно-частного партнерства, однако в научной литературе этот аспект практически не исследовался.

В данной статье мы хотели привлечь внимание к необходимости уточнения роли и места негосударственных структур безопасности и охранных организаций в системе антитеррористической защищенности промышленных объектов и законодательства в данной сфере с учетом зарубежного опыта. Для хозяйствующих субъектов решение указанных вопросов имеет не только теоретическое, но и практическое значение, поскольку самым непосредственным образом влияет на формирование адекватной угрозам структуры и экономически обоснованной штатной численности подразделений корпоративной безопасности; внедрение новых форм и методов противодействия терроризму, оценки эффективности данной деятельности.

Возникает вопрос: насколько отечественные тенденции взаимодействия государства и служб безопасности коммерческих структур в сфере противодействия терроризму соответствуют мировым?

Ранее мы отмечали, что по отношению к государственной системе противодействия терроризму антитеррористическая система корпоративной безопасности представляет собой отдельную подсистему. Общегосударственная система, безусловно, оказывает влияние на каждую локальную корпоративную систему, определяя подходы к формированию угроз, перечню субъектов, их функций и полномочий, методам и средствам антитеррористического воздействия. Вместе с тем это не исключает учета особенностей, а нередко и уникальности конкретного предприятия. В свою очередь, учет этих особенностей и имеющегося опыта защиты объектов оказывает обратное влияние на общегосударственную систему, совершенствуя применяемые средства и методы.

Анализ тенденций в данной сфере позволяет утверждать, что до недавнего времени государство хотя и включало негосударственные структуры безопасности в общую систему, но отводило им второстепенную роль в противодействии терроризму. На политическом уровне декларировалась необходимость активного включения бизнеса в антитеррористическую борьбу2 ${ }^{2}$ Однако на практике она сводилась к получению сигналов о готовящихся террористических проявлениях, устранению обстоятельств, им способствовавших, в ряде случаев - к финансированию антитеррористических мероприятий.

Анализ внутренних взаимосвязей общегосударственной системы противодействия терроризму показывает, что на данный момент наиболее «нагружен-

\footnotetext{
1 Проекты Ф3 «О частной детективной деятельности» и «О частной охранной деятельности».

2 Не случайно п. 9 Стратегии партнерства государств и бизнеса в противодействии терроризму гласит: «Для обеспечения защиты от терроризма жизненно важно наладить эффективное взаимодействие между правительствами и бизнесом, задействованным в соответствующих сферах, в том числе посредством интенсивного обмена информацией и опытом. Для обеспечения достаточного уровня безопасности в общих интересах может потребоваться принятие определенных мер регулирования». См.: Стратегия партнерства государств и бизнеса в противодействии терроризму. Принята на Глобальном форуме по партнерству государств и бизнеса в противодействии терроризму. Москва, 30 ноября 2006 г.
} 
ными» являются подсистемы силового противодействия. Видимо, поэтому суть взаимодействия сводится к усилению контроля за негосударственными структурами безопасности. Жесткие, а порой и избыточные ограничения, связанные с добыванием информации, использованием оружия и спецсредств, накладывает законодательство о частной детективной и охранной деятельности, которое является базовым для корпоративных структур безопасности. Фактически государственные органы стремятся сохранить за собой монополию на безопасность. Такой подход мотивируется тем, что якобы квалификация у сотрудников государственных служб значительно выше, чем в частных компаниях. Данный тезис весьма сомнителен, поскольку в сферу частных услуг приходят бывшие сотрудники правоохранительных органов и спецслужб, обладающие той же компетенцией, что и действующие сотрудники, но с неизмеримо большим опытом работы.

В последние годы ситуация стала меняться. В условиях сокращения финансирования силового блока корпоративным службам безопасности и привлекаемым охранным предприятиям де-факто передаются все новые участки противодействия терроризму. Так, в 2016 г. (после крупнейшего сокращения штатов вневедомственной охраны) в МВД РФ разработан законопроект, который в случае его принятия позволит переложить часть функций полицейских на частные охранные предприятия. Например, объектовую охрану будут привлекать к охране порядка и антитеррористической защите объектов и прилегающих территорий, а частных детективов - к профилактике и расследованию преступлений, в т.ч. и террористической направленности ${ }^{1}$. Такой подход особенно актуален для территорий, где предприятия являются системообразующими (например, Норильский промышленный район). Появление данного законопроекта показывает, что государству выгодно развитие негосударственной сферы безопасности, поскольку она не требует бюджетных средств. По имеющимся сведениям, на ведомственном уровне идет активная подготовка предложений, направленных на перераспределение функций между государственными и негосударственными субъектами противодействия терроризму, при этом последним отводится более активная, наступательная роль.

Мы считаем, что данная тенденция в полной мере учитывает положительный зарубежный опыт государственно-частного партнерства в данной сфере. Правительства многих западных стран передают в частные руки виды деятельности, которые раньше считались исключительной прерогативой государства. В Израиле сотрудникам корпоративных служб безопасности нормативно предписывается функция выявления и предупреждения террористических проявлений. Сотрудников служб безопасности и частных охранных компаний активно используют на наиболее уязвимых в террористическом отношении направлениях. Их оснащение и вооружение соответствует таковым у полиции. Они осуществляют антитеррористическое обеспечение не только промышленных объектов, но и важнейших правительственных и транспортных объектов (в частности, авто- и железнодорожных станций, аэропортов и т.д.). Начиная с 2009 г. они стали замещать государственные службы на пограничных пунктах в секторе Газы. Корпоративные структуры активно участвуют

\footnotetext{
1 «В условиях сокращения численности и финансирования органов внутренних дел, а также пересмотра перечней объектов, охраняемых в том числе полицией, остро встал вопрос обеспечения антитеррористической защищенности данных объектов, охраны общественного порядка и обеспечения безопасности граждан, снижения издержек государства на охрану государственных и муниципальных объектов», - говорится в пояснении к законопроекту МВД.
} 
в выявлении террористов, передавая данные спецслужбам и пограничным органам ${ }^{1}$ [Фурсова 2014].

Частные охранные и частные военные компании из Великобритании, Венгрии, Франции и Канады активно привлекаются для не только для охраны важных объектов промышленности и транспорта, но и для охраны важнейших государственных органов и диппредставительств ЕС, в т.ч. за рубежом и в «горячих точках» (Ливан, Афганистан, Ливия, Сирия и т.д.) В Брюсселе - фактической столице Евросоюза - охрану комплекса зданий ЕС, Еврокомиссии, Совета ЕС и Европарламента несут более тысячи сотрудников частной английской фирмы $G 4 S$. Такая же ситуация складывается и в США, где частным военным компаниям переданы не только конвойно-охранительные, но и антитеррористические функции (Афганистан, Сирия и т.д.). Таким образом, за рубежом налицо тенденция расширения функций негосударственной сферы безопасности в области противодействия терроризму. При этом полномочия зарубежных компаний детально регламентированы в корпоративных нормативных актах, в которых определяются угрозы безопасности, силы и средства, направленные на нейтрализацию этих угроз.

Подавляющее большинство крупных российских компаний, исходя из особенностей предприятия, также создают внутренние нормативные акты, определяющие подходы к корпоративной безопасности. Они имеют подчас разные названия, но по существу содержат аналогичные основные параметры корпоративной безопасности. Такой подход предполагает формирование адекватных внутренним и внешним угрозам функций корпоративной безопасности, которые предопределяют линии работ и, соответственно, структуру данных служб. Нами изучены нормативные акты такого рода 10 крупнейших российских компаний. Они имеют различные названия (концепции, комплексные программы, регламенты) и являются методологической основой для проведения единой политики в области корпоративной безопасности, учитывают ее современное состояние и перспективы развития. Все они имеют свои особенности, но структурно, как правило, включают несколько разделов: угрозы безопасности, цели, субъекты, принципы, структура и система организации и т.д.).

Важнейшим разделом каждой из этих концепций являются угрозы корпоративной безопасности и направления ее обеспечения. Мы обратили внимание, что наиболее отработанные нормативные документы к числу основных угроз корпоративной безопасности относят террористические акты, важнейшим источником угроз определяют террористические организации, которые по степени ранжированности указаны на первом месте 2 .

К сожалению, концепции некоторых инфраструктурных компаний не выделяют прямо терроризм как угрозу корпоративной безопасности, что, по нашему мнению, является упущением. Мы полагаем, что антитеррористическая защищенность является одной из функций обеспечения корпоративной безопасности, что должно быть отражено в корпоративных нормативных актах.

Реализация функции противодействия терроризму происходит в ходе осуществления традиционных направлений деятельности (экономическая, внутренняя безопасность, расследование, охрана, информационно-аналитическая

\footnotetext{
${ }^{1}$ В настоящее время власти Англии, опасаясь, что окончание активных военных действий в Сирии приведет к возвращению в страну людей с навыками террористических действий, готовят правовые и организационные меры к ограничению их въезда в страну, лишению участников боевых действий в Сирии британского подданства.

2 В качестве примера можно привести п. 6 ст. 26 и п. 1 ст. 27 Концепции корпоративной безопасности ОАО РЖД, утвержденное распоряжением от 20 декабря 2010 г. N 2628p; Концепцию комплексной системы безопасности ОАО «Горно-металлургическая компания «Норильский никель» и т.д.
} 
деятельность), поскольку работа большинства структур корпоративной безопасности строится по линейно-объектовому принципу. Например, в ходе осуществления функции экономической и внутренней безопасности они своевременно информируют правоохранительные органы о подозрительных лицах, фирмах, конкретных фактах, имеющих террористическую направленность, в отдельных случаях выявляют и блокируют каналы финансирования террористических организаций. Как известно, действующее законодательство (посредством заключения гражданско-правовых договоров с детективами) создает возможности для участия негосударственных служб безопасности в предупреждении и раскрытии преступлений, сборе сведений по уголовному делу на основании договора с участниками уголовного судопроизводства, допускает устный опрос граждан и должностных лиц (с их согласия), наведение справок, изучение предметов и документов (с письменного согласия их владельцев), внешний осмотр строений, помещений и других объектов, наблюдение, использование видео- и аудиозаписи, кино- и фотосъемки, технических и иных средств, не причиняющих вреда жизни и здоровью граждан и окружающей среде ${ }^{1}$. По своей сути эти средства имеют сходную гносеологическую природу с методами, используемыми правоохранительными органами в соответствии с законодательством об оперативно-розыскной деятельности (оперативное наблюдение, выведывание, опрос, осмотр, оперативный эксперимент и т.д.).

Однако, по нашему мнению, в современных условиях этого недостаточно. Наряду с выявлением признаков террористической деятельности, корпоративные службы безопасности (во взаимодействии с кадровыми подразделениями) могут и должны принимать меры общей и частной профилактики в рамках имеющихся полномочий и в соответствии с действующим законодательством, активнее выявлять правонарушения и принимать меры по устранению причин и условий, способствовавших их совершению.

Существенный вклад в противодействие терроризму вносят и охранные организации. Они не только самым непосредственным образом вовлечены в антитеррористическую защиту промышленных объектов, потенциально опасных в антитеррористическом отношении, но и реально являются неотъемлемой частью сложившейся системы безопасности населенных пунктов и территорий, объектов транспорта и инфраструктуры. Таким образом, частные охранные организации не только защищают права и законные интересы бизнеса, но и принимают активное участие в решении государственной задачи по предупреждению и пресечению актов терроризма.

Вместе с тем, на наш взгляд, регламентация нормативных предписаний, направленных на взаимодействие подразделений частной охраны с правоохранительными органами и специальными службами, должна быть конкретизирована.

Изложенное позволяет сделать следующие выводы.

1. Необходимо создать условия для использования потенциала негосударственных структур безопасности, охранных организаций в общегосударственной системе противодействия терроризму как элемента обеспечения национальной безопасности.

2. Целесообразно разработать и принять основные направления государственной политики для вовлечения потенциала негосударственных структур безопасности в деятельность по противодействию терроризму. Такая политика должна предполагать структурные, правовые и организационные мероприятия.

\footnotetext{
1 Федеральный закон «О частной детективной и охранной деятельности в Российской Федерации». Ст. 5.
} 
3. В правовой сфере: на уровне федерального законодательства (с учетом зарубежного опыта) необходимо конкретизировать перечень и распределение ответственности государственных и негосударственных субъектов противодействия терроризму, предоставив последним более широкие полномочия (расширить права частных охранников и детективов, права предприятий на привлечение негосударственной охраны и др.)

4. На ведомственном уровне необходимо совершенствовать нормативную базу взаимодействия ФСБ России с негосударственными структурами безопасности, частными детективами и охранными организациями, развивать механизмы этой координации. С этой целью следует разработать и установить единую форму совместных планов обеспечения антитеррористической защиты объектов (включая периодичность обследования, их паспортизацию, оценку эффективности антитеррористической защиты объекта, проверку наличия и работоспособности технических средств охраны, порядок действий в различных ситуациях, обмен информацией о признаках террористической деятельности, миграционную обстановку, анализ эффективности работы антитеррористических комиссий и комплексных целевых программ, проведение совместных антитеррористических учений и т.д.).

5. В корпоративных правовых актах (концепциях корпоративной безопасности террористически уязвимых объектов) прямо должны предусмотрены нормативные предписания, включающие терроризм в перечень основных угроз безопасности, а также перечислены конкретные меры, силы и средства противодействия терроризму.

\section{Список литературы}

Воронов А.М. 2017. Институты гражданского общества в негосударственной системе обеспечения национальной безопасности современной России. - Вестник Пермского университета. Вып. 35. С. 33-41.

Гасумянов В.И. 2018. Корпоративная безопасность в системе обеспечения национальной безопасности Российской Федерации: теоретические аспекты. - Власть. Т. 26. № 1. С. 7-21.

Фурсова Е.Б. 2014. Гражданское общество и противодействие терроризму. Вестник Московского университета МВД России. № 9. С. 78-81.

Шестаков В.И. 2017. Негосударственная сфера безопасности, охранная деятельность, частный сыск. В 5 т. М.: Радио Софт.

\section{THE ROLE AND PLACE OF NON-STATE SECURITY STRUCTURES IN THE COUNTRY'S ANTI-TERRORIST SECURITY SYSTEM}

Abstract. The article analyzes the place of non-state security and safety structures in the national system of counterterrorism in modern conditions. The author considers counteraction to terrorism in the system of corporate security functions. Keywords: corporate security structures, counter-terrorism, system of corporate security functions 